\title{
Arbor
}

\section{El comunitarismo en los pueblos indígenas de México}

\section{Regina Jiménez Ottalengo}

Arbor CLXV, 652 (Abril 2000), 747-757 pp.

Los pueblos indigenas mexicanos son culturas postergadas que sobreviven gracias a una organización comunal basada en un sistema de cargos cívico religiosos de carácter democrático y rotativo y que les imprime un sello corporativo. Su cohesión esta sustentada por los núcleos domésticos que se articulan entre si, por la vía de la solidaridad y la ayuda recíproca.

De acuerdo a Etzioni ${ }^{1}$ todos los sistemas de pensamientos y de creencias se construyen sobre la base de un concepto axial, así para los individualistas, una sociedad armónica («buena sociedad») tiene como sustento a la persona libre, para los social conservadores es un conjunto penetrante de virtudes sociales que cristalizan en la sociedad o el estado; para los comunitarios la base se da en el equilibrio entre autonomía y orden, un orden convencional acotado por valores nucleares y autonomía contextual en una red de vínculos y valores.

En la mayoría de los pueblos indígenas mexicanos se vive, hasta la fecha, un comunitarismo basado en tres valores fundamentales compartidos: 1) autoridad rotativa como base de la organización comunal, 2) la solidaridad y 3) la ayuda mutua. Las sociedades indígenas mexicanas son núcleos pequeños, generalmente aislados, con elevados índices de analfabetismo.

Grupos homogéneos con gran sentido de solidaridad, comportamientos tradicionales que tienen como base de organización social el paren-. tesco y como unidad de acción a la familia. Su cultura gira alrededor de lo sagrado y su economía en torno al prestigio más que al mercado. 
Los núcleos indígenas son culturas postergadas que no han podido despegar por falta de un respaldo oficial y de políticas adecuadas, lo que ha permitido una explotación constante que les impide enfrentarse a la sociedad global dominante, sin embargo han sobrevivido al empuje de los centros rectores y a las metrópolis económicas que los dominan, gracias a la fuerte cohesión de sus societarios.

\section{El entorno}

Los indígenas se caracterizan, entre otras cosas, por la lengua que hablan, porque conservan sus tradiciones para vincularse con la naturaleza, sus semejantes y para organizarse para el trabajo y el ocio, pero especialmente porque se identifican como tales. Con este criterio el Instituto Nacional Indigenista realizó un estudio titulado Indicadores Socio Económicos de los pueblos Indígenas de México (1990), en el se estima que alrededor de nueve millones de personas son indígenas, esto es, el $10 \%$ de la población total del país. La población indígena se concentra en el sudeste de la República Mexicana, especialmente en los estados de Oaxaca, Veracruz, Chiapas, Puebla y Yucatán.

De los municipios con $30 \%$ o más de población indígena estimada, más de la mitad presentan una alta marginación. En cuanto a los indicadores sobre nivel educativo, el $46.1 \%$ es analfabeta; la población de 15 años y más sin primaria completa es el $75.9 \%$; monolingües son el $24.8 \%$.

En cuanto a indicadores de bienestar, la población indígena carece de electricidad en un 51.6\%; el $68.3 \%$ carece de agua entubada; el $90.4 \%$ no dispone de drenaje; el $76.4 \%$ tiene piso de tierra en su vivienda. Como puede observarse las condiciones socioeconómicas son precarias, por otro lado, la diversidad lingüística de los pueblos indígenas de México es muy elevada ya que existen cuando menos 59 lenguas diferentes, lo que muestra un mosaico de expresiones culturales en donde las únicas constantes son su organización comunal y la pervivencia de su solidaridad y ayuda mutua.

\section{La organización comunal}

Es una red de relaciones que se genera en los grupos domésticos y se extiende a los barrios que conforman el área física de los pueblos. Esta red se sostiene mediante un sistema de cargos cívico religiosos que le da un carácter básicamente corporativo y les permite conservar sus rasgos culturales más preciados: su lengua, sus costumbres y sus tradiciones. El 


\section{El comunitarismo en los pueblos indígenas de México}

sistema de cargos cívico religioso es el mediador de todas las relaciones: la administración, la iglesia y el trabajo colectivo.

En casi todas las comunidades indígenas mexicanas prevalece la misma organización comunal heredada del período colonial, implantado por los españoles y alentado por la Iglesia Católica. Su conformación se facilitó por el tipo de estructura que existía en el período prehispánico y que tenía como característica el ser una estructura democrática.

Los españoles procuraron que los indígenas conservaran algunas de sus costumbres y las que modificaron lo hicieron adecuándolas a los rasgos originales, lo que permitió a los grupos indígenas preservar muchas de sus tradiciones y mantener sus particularidades y algunas de sus instituciones reforzaron especialmente la solidaridad entre sus miembros, alentados por los evangelizadores y apoyados por la acción protectora de los misioneros, respaldadas a su vez por las autoridades civiles.

\subsection{Desarrollo de la organización comunal}

En el siglo XVIII, la organización comunal se denominó República de Yndios y en ellas se estabilizó poco a poco el sistema de cargos civiles y religiosos. Se les dotó de territorio propio respaldado por una serie de documentos agrarios, se mantuvo el sistema de cargos, se alentó el trabajo colectivo, se desarrollaron cajas de comunidad, todo lo cual permitió el aislamiento y la permanencia de instituciones propias ${ }^{2}$. Desde la mitad del siglo XVI, el poder local se constituyó igual que el del cabildo español compuesto por una gran variedad de puestos. Durante las primeras épocas de la colonia, el jefe local precolombino Tlahtoani (cacique) asumió el poder, pero más tarde, en el siglo XVII se instituyen los cargos jerárquicos anuales y rotativos.

Con la Independencia se consideró que ya no débería habêr diferencias entre los ciudadanos criollos, los mestizos, los africanos y los indígenas, lo que dio como resultado la terminación de actitudes protectoras y de excepción, así como de leyes especiales para los indígenas. Los hospitales, los colegios, las cajas municipales y, especialmente la propiedad comunal, deberían desaparecer ya que el indígena requería convertirse en sequeño propietario, por lo que la tiérra se dividió en parcelas Sin emrargo sobrevivió el sistema de cargos y la organización comunal.

\section{.2. La organización comunal actual}

Si bien es cierto que en la actualidad han tenido modificaciones, su configuraciôn es básicamente la misma. Sigue siendo un sistema recíproco de responsabilidades, donde el hombre de entre 20 y 60 años, que 
sea jefe de familia, tiene la obligación de dar un año de servicio en el sistema de cargos cada tres o cuatro años. Los cargos son 25 y duran un año. Otros cargos menores duran más tiempo ${ }^{3}$.

En una fecha fija anual, se escoge a los encargados de cada puesto para el siguiente año. Todos los cargos son honoríficos por lo que los elegidos deben ser solventes y vigilar y administrar los intereses de la comunidad. Los cargos son repartidos entre los monahiit («aquellos con trabajo» en lengua huave) es decir aquellos que en ese año deben cuidar el funcionamiento tanto político, como judicial, administrativo y religioso del pueblo. A estos monahiit la comunidad les propone dos tipos de cargos, el civil o el religioso, y ellos deciden y escogen el tipo de puesto a desempeñar.

En el sistema civil los puestos de más alta jerarquía son el de presidente municipal y el de alcalde. El de menor jerarquía es el de topil, policía bajo el mando de los otros dos. Entre las funciones de los topiles está la de garantizar el orden, el ser mensajeros y guardianes de las otras autoridades. Existe también el cargo de pregoneros, difusores de noticias de interés comunitario y sirven de enlace entre las autoridades civiles y religiosas.

Los regidores, que dependen directamente del presidente municipal, se encargan de la limpieza del pueblo y de asesorar al presidente municipal y al alcalde. Otros cargos son: tesorero, escribano y síndico, que tienen como funciones: el primero de éstos, recoger los impuestos; el segundo, llevar el recuento de los contribuyentes así como el registro de propiedades y el último funge como mediador con el ministerio público del centro urbano más cercano a la localidad.

A los cargos jerárquicamente dispuestos, se accede por escalafón siempre y cuando hayan cumplido con los deberes comunitarios, que tengan solvencia moral así como prestigio social y que en años recientes hayan sido mayordomos, puesto religioso de alto aprecio colectivo.

Existe un consejo de ancianos integrado por hombres de entre 50 y 60 años, cuyo prestigio se debe a que desempeñaron con acierto sus cargos civiles y/o religiosos. Su función dentro de la organización civil es la de aconsejar y orientar a la autoridad en turno. El encargado de citar al consejo es el presidente municipal, y es este quien se encarga de plantear el problema o proyecto, una vez acordado con el grupo de ancianos, estos son los responsables de párticiparlo a la asamblea y de sensibilizar a la mayoría, para su aprobación o rechazo.

\subsection{Los cargos religiosos}

El sistema de cargos religiosos es menos complejo y numeroso que el civil. El grado más bajo es el de «pequeño acólito» que lo ejercían adoles- 
El comunitarismo en los pueblos indígenas de México

centes y jóvenes célibes, son una especie de aprendices a los que se les instruye en la doctrina, las oraciones y el servicio de la misa y obligan a mantener la limpieza del templo. De acólito se pasa a topil de la iglesia, quien se encarga de la difusión de mensajes religiosos. El ascenso siguiente es el de sacristán, después de fiscal y por último el de maestro de capilla, quien se ocupa de la organización y registro de feligreses.

\subsection{La mayordomía}

Para lograr los cargos de más alta jerarquía en el sistema civil, se requiere del prestigio que otorga la mayordomía, una institución ligada al ritual festivo de los santos patronos del pueblo. La persona que se compromete a servir como mayordomo debe efectuar fuertes erogaciones económicas para celebrar la festividad de cada santo patrono, entre otras cosas, debe ofrecer alimentos especialmente elaborados, a todas las personas que acuden al barrio en que se celebra la festividad. Esta dura una semana en la que el mayordomo ofrece la comida, las bebidas embriagantes y los cigarrillos.

La obligación del mayordomo, además de patrocinar la fiesta del santo, consiste en acudir tres veces por semana en la madrugada y por espacio de un año, a poner velas y veladoras al santo patrón, así como a rezar en compañía de otros hombres que han desempeñado la misma función.

Todo este sistema de cargos se ha visto seriamente amenazado por la intromisión del Estado y por la economía de mercado.

\section{La solidaridad}

En los pueblos indígenas, especialmente en la zona ubicada en los estados del sur: Oaxaca, Chiapas, Guerrero, se realiza una actividad conocida como tequio, tarea o faena (Tzina Yeetzi, en zapoteco, trabajo del pueblo). Consiste en llevar a cabo alguna obra de beneficio social. En este tipo de trabajo solidario copera toda la unidad doméstica. Como se relató anteriormente, los ciudadanos tienen obligación de dar un año de servicio en el sistema de cargos cada tres o cuatro años. Como autoridades organizan y vigilan el trabajo comunal y anuncian las labores que deberán realizarse, también agrupan a los ciudadanos de la comunidad para realizar los trabajos por turnos. Cuando algún ciudadano no puede acudir a las labores, envía a otra persona en su representación, toda vez que aquel que no cumple con su compromiso, es sancionado. Cuando el grupo fami- 
liar esta dirigido por mujeres solas, tienen al igual que sus familiares, las mismas obligaciones y derechos. Regularmente las mujeres cooperan llevando alimentos a los grupos de trabajo.

La familia de cada una de las autoridades pone todos sus recursos a disposición de la comunidad, usan sus propios utensilios, animales y demás bienes. Los «que sirven», es decir, los que tienen el cargo honorífico anual buscan el apoyo de familias amistades y compadres fuera de su núcleo familiar, para realizar las obras de beneficio colectivo: abrir calles; así como construir, remodelar y dar mantenimiento a: jardines, oficinas municipales, escuelas, en fin, obras materiales de uso común.

Aunque es cierto que los lazos de asistencia solidaria tienden a desaparecer, ante el empleo de asalariados y la emigración de los jóvenes en busca de mejores oportunidades de vida, así como la aparición de sectas religiosas, la tradición se mantiene. Se da el caso que aun lejos de sus comunidades colaboran. Es frecuente ${ }^{4}$ que los que han emigrado a la capital del país o a los Estados Unidos de Norte América, se integren en círculos donde celebran asambleas para ayudarse mutuamente y para enviar a su pueblo natal colaboraciones monetarias, lo mismo para terminar de construir un templo o una escuela que para abrir carreteras, o para impulsar la labor de las escoletas (escuelas de música tradicional).

En algunas ocasiones colaboran con material de construcción y con la asesoría de profesionales nativos, que laboran en otras regiones, pero que no olvidan su obligación comunitaria. Como las mujeres ya son consideradas ciudadanas, también contribuyen a las obras voluntarias, ya sea ayudando en las cosechas o al desgrane del maíz, y en las festividades se encargan de la preparación de los alimentos. Muchas veces la ayuda de las mujeres consiste en hacerse cargo de la manutención familiar, a fin de que sus esposos cumplan con los cargos comunitarios. ${ }^{5}$

\section{La ayuda mutua}

En las comunidades indígenas tienen por costumbre ayudarse entre parientes, compadres, vecinos y amistades. Se prestan bienes, animales y se auxilian unos a otros con trabajo personal. Regularmente la ayuda se proporciona recíprocamente, a nivel de unidades domésticas, no de individuos. Las obligaciones y derechos son hereditarios, lo que asegura la continuidad del compromiso ${ }^{6}$.

En las comunidades zapotecas de Oaxaca se conoce a este sistema de ayuda mutua con el nombre de gozona $(\mathrm{Gwzon})^{7}$. Esta ayuda recíproca se lleva a cabo en los trabajos agrícolas mediante acuerdos tomados entre 
ellos en que organizan las faenas y los tiempos. También se utilizan en las festividades religiosas, en los casamientos, en las defunciones y en la construcción de casas.

En las tres últimas décadas la región del sudeste del país, en donde habitan pueblos mixes, zapotecas, huaves, mayas y otros grupos indígenas, se incorporaron al comercio internacional, mediante la producción de café, y lo hicieron en un principio con relativo éxito. Sin embargo, con la caída del precio de ese producto, han sufrido desajustes económicos que dieron como resultado que su sistema tradicional de subsistencia se viera afectado. Con la siembra de cafetos la tierra se erosionó, recibieron poca paga y dejaron de sembrar frijol y maíz, base de su dieta diaria.

Este fracaso en su economía no les hizo perder su sentido de solidaridad, así los pequeños agricultores se han integrado en grupos de cuatro a seis personas, para trabajar la tierra con la practica de «manovuelta». Consiste en que cada grupo se ayuda por turnos en la preparación del terreno, la siembra y la cosecha. Es una estrategia de ayuda mutua que han ejercido tradicionalmente y de la cual han hecho uso en estos tiempos de crisis para evitar el empleo de peones asalariados y con ello reducir costos de producción. ${ }^{8}$

\subsection{Festividades religiosas}

En las festividades religiosas, el mayordomo tiene la obligación de cuidar y rezar frente a la imagen del santo patrono. El día del santo el mayordomo debe ofrecer los festejos, por ello una semana antes los habitantes del pueblo empiezan a visitar al mayordomo para ofrecerle su ayuda. Algunos llevan obsequios para aminorarle la carga económica. El mayordomo toma nota de lo que recibe para que cuando al otro le toque el cargo, el pueda corresponderle.

Todo lo que se ocupa para la fiesta es proporcionado por las familias de la localidad. Los festejos tienen una duración de varios días, en algunas ocasiones de una semana entera. Al término de la fiesta, los enseres prestados son devueltos a sus dueños acompañados de alimentos.

\subsection{Casamientos}

En los casamientos, la fiesta se realiza cuando se lleva a cabo la ceremonia religiosa. Para la realización del festejo cooperan familiares y amigos. Esta cooperación es vigilada por los padres de los novios, de tal forma que cuando deban corresponder a los que les han ayudado lo hagan en forma similar. 
La boda dura de dos a tres días, dependiendo de la situación económica de los desposados. En esos días se proporciona alimento y bebidas alcohólicas acompañadas de música ejecutada por los integrantes de la escoleta. Los padrinos de los contrayentes regalan el aguardiente y los adornos de la iglesia, los contrayentes a su vez obsequian a sus padrinos algún animal doméstico, sellándose, de esta manera, un fuerte compromiso entre ahijados y padrinos. Los desposados se consideran hijos adoptivos y tienen la obligación de prestar ayuda a sus padrinos cuando éstos la soliciten.

\subsection{Defunciones}

Las defunciones son anunciadas con toque de campanas. Cuando se dan cita en la casa del difunto para la ceremonia de velación, se regalan velas, veladoras y dinero. Todos ayudan en la ceremonia por que saben que en su momento, también recibirán apoyo. En los funerales se da café, bebidas alcohólicas y pan; la banda toca música alusiva. Al día siguiente del entierro se acude al arroyo o río más cercano para bañarse y lavar la ropa utilizada en el sepelio. ${ }^{9}$

\subsection{Construcción de casas}

En la construcción de casas se invita a los parientes y amistades para realizar la obra. Para iniciar el compromiso, el futuro dueño ofrece un almuerzo en donde se invoca la bendición de Dios, para que los esfuerzos den buenos resultados y no haya accidentes ni contratiempos. Terminado el almuerzo, los ancianos invitados sirven bebidas embriagantes (mezcal) y riegan licor en los cuatro ángulos del sitio en que se va a fincar. Se reparten tareas y se inician las labores, los trabajadores comen en el propio lugar de trabajo atendidos por las mujeres del grupo que de esta manera cooperan. Queda claro que ninguno recibe paga por su trabajo.

\section{Prestigio}

El código simbólico que marca el prestigio en los pueblos indígenas esta íntimamente ligado al sistema de cargos, especialmente a la mayordomía y al intercambio recíproco. Ambos se fundamentan en el respeto que se obtiene por cumplir con las obligaciones de carácter comunitario. Por otra parte, el gasto suntuario que se realiza en las fiestas rituales contribuye a crear una buena imagen entre la población, que ve con agra- 
do el gasto para beneficio social y lo reprueba cuando es de provecho individual o privado. ${ }^{10}$

\section{El cambio y la modernidad}

Los pueblos indígenas mexicanos se encuentran en un proceso de cambio que hace temer la perdida de su vida comunitaria. Por un lado la intervención del Estado ha introducido nuevas funciones políticas que entran en rivalidad con el sistema de cargos tradicional; y por el otro la incorporación al mercado nacional e internacional que ha desarrollado una diferenciación económica entre los grupos domésticos.

Las políticas gubernamentales han buscado la desaparición de la autosuficiencia de las comunidades y desdibujar la presencia del sistema de cargos con el objeto de conectarlos a los círculos de producción moderna que solo ha servido para explotar a esos pueblos, lo mismo los montes de la Sierra Tarahumara que la fuerza de trabajo de los mayas de Chiapas que el café de los mazatecos, que los sombreros mixtecos.

A esto hay que agregar la entrada de las sectas religiosas que han dividido a las familias, a los barrios y a los pueblos. Por otro lado la influencia de los medios de difusión han minado el espíritu solidario y unificador de las instituciones indígenas, lo que provoca a menudo miseria física y moral.

\section{Reflexión final}

A pesar de las múltiples intervenciones que ponen en peligro las tradiciones y la cohesión de las comunidades indígenas, éstas no han perdido del todo su identidad y buscan en sus raíces comunitarias una vía de sobrevivencia. El valor de la comunidad como entorno de excelencia social queda en este caso de estudio refrendado. Muchos de los indígenas que emigran y que han logrado triunfar económica o profesionalmente hablando, consideran que ese camino de solidaridad, aunado a una educación cívica ${ }^{11}$ integral puede hacer que las culturas y comunidades indígenas persistan y logren amalgamarse a la cultura y comunidad nacional, para alcanzar un progreso que les permita influir en la vida del país nutriendo a la sociedad global con su visión solidaria y de ayuda mutua para llevarla por senderos de justicia y unidad.

Esto no es fácil, básicamente por dos factores: uno, el individualismo que invade a los miembros de la sociedad global mexicana y dos, que la 
cultura indígena no es valorada por esa sociedad, a pesar de los valores intrínsecos de su visión de la vida. Es por ello que se requiere hacer de los pueblos indígenas objeto de estudio de la antropología comunitarista que reivindique su mundivisión y que se deje de ver a estos grupos sólo como sociedades Folk utilizadas solo para enriquecer el acervo antropológico y para el esparcimiento turístico. En la apuesta comunitarista que nos presentan Etzioni y otros autores, el ejemplo de estas colectividades es una pauta a seguir.

\section{Notas}

1 Amitai Etzioni. La nueva regla de oro. p.49.

2 Guillermo Bonfil designa este hecho como "enquistamiento" de la comunidad indígena.

3 ItAlo Signorini. Los huaves de San Mateo del Mar.

4 Ignacio Mansilla (coord.). Sierra Juárez. Trabajo Comunitario. pp.79-81.

5 Beatriz Vargas ZaCARIAS. "Responsabilidad de la mujer en el tequio". Sierra Juárez. Trabajo Comunitario, p. 181.

6 Catharine Good Eshelman. Haciendo la Lucha,. p. 168.

7 Oscar Alvaro Cruz Díaz. La Solidaridad Social Como Base de la Resistencia a Partir del Intercambio. p.106.

8 Martín Aguilar Domingo. «Zacatepec y su porvenir» en Sierra Juárez. Trabajo Comunitario, p.86.

9 Oscar Alvaro Cruz Díaz. Op. cit. p. 112.

10 Daniele Dehauve. El Tequio de los Santos y la Competencia Entre los Mercaderes, p. 299.

11 Dice Alejandro LlaNo que: "La educación cívica solo es posible en el seno de comunidades humanas abarcables. En esas comunidades de indagación y enseñanza, el aprendiz se adiestra en el oficio de la ciudadanía que - como todos los oficios - tiene mucho más de craft, de artesanía, de lo que la razón ilustrada esta dispuesta a reconocer". Qué más abarcable que estas nuestras comunidades indígenas que mucho saben de oficios y artesanías.

\section{Bibliografía}

Bonfil Batalla G. México Profundo. Una Civilización Rezagada. México, ed.Grijalvo y Consejo Nacional para la Cultura y las Artes, 1989.

Cruz Alvaro O. La Solidaridad Social Como Base de la Resistencia a Partir del Intercambio (Gwson), Patzcuaro, Mich. México. Tesis 1982.

Dehouve D. El Tequio de los Santos y la Competencia Entre los Mercaderes. México, Instituto Nacional Indigenista y Secretaría de Educación Pública, 1976.

Embriz Osorio A. (Coordinador): Indicadores Socioeconómicos de los Pueblos Indígenas de México. 1990. México, Instituto Nacional Indigenista, 1994. 


\section{El comunitarismo en los pueblos indígenas de México}

Etzioni A.: La nueva Regla de Oro. Comunidad y Moralidad en una Sociedad Democrática. Trad. Marco Aurelio Galmarine, Barcelona, Paidós, 1999.

Good Eshelman C. Haciendo la Lucha. Arte y Comercio Nahuas de Guerrero. México, Fondo de Cultura Económica, 1988.

Llano A. «La Verdad en la Conversación Humana. Una Consideración Entre Liberalismo y el Comunitarismo" en Nuñez Ladevere, Luis: Etica Pública y Moral Social. Madrid, Noiesis, 1996.

Martín Aguila D. «Zacatepec y su Porvenir», en Mancilla Ignacio (Coordinador), Sierra Juárez Trabajo Comunitario, México, Instituto Nacional Indigenista, 1994.

Pozas Ricardo A. y De Pozas I. H. Los Indios de México en las Clases Sociales de México. México, Siglo XXI, 1987.

Signorini I. Los Huaves de San Mateo del Mar. México, Instituto Nacional Indigenista y Consejo Nacional de las Artes, reimpresión 1991.

VARGas ZaCARIAS B. "Responsabilidad de las Mujeres en el Tequio. en Mancilla, Ignacio (Coordinador): Sierra Juárez. Trabajo Comunitario. México, Instituto Nacional Indigenista, 1994. 